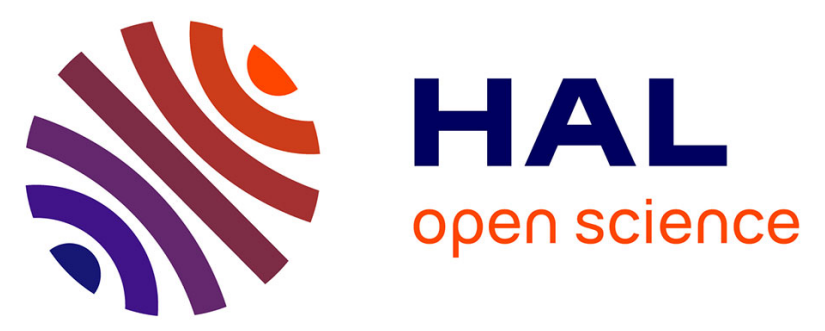

\title{
Influence of microwave treatment on the structure and functionality of pure amylose and amylopectin systems
}

Yuyue Zhong, Yu Tian, Xingxun Liu, Li Ding, Jacob Judas Kain

Kirkensgaard, Kim Hebelstrup, Jean-Luc Putaux, Andreas Blennow

\section{> To cite this version:}

Yuyue Zhong, Yu Tian, Xingxun Liu, Li Ding, Jacob Judas Kain Kirkensgaard, et al.. Influence of microwave treatment on the structure and functionality of pure amylose and amylopectin systems. Food Hydrocolloids, 2021, 119, pp.106856. 10.1016/j.foodhyd.2021.106856 hal-03220097

\section{HAL Id: hal-03220097 https://hal.science/hal-03220097}

Submitted on 10 May 2021

HAL is a multi-disciplinary open access archive for the deposit and dissemination of scientific research documents, whether they are published or not. The documents may come from teaching and research institutions in France or abroad, or from public or private research centers.
L'archive ouverte pluridisciplinaire $\mathbf{H A L}$, est destinée au dépôt et à la diffusion de documents scientifiques de niveau recherche, publiés ou non, émanant des établissements d'enseignement et de recherche français ou étrangers, des laboratoires publics ou privés. 


\section{Influence of microwave treatment on the structural and functionality of pure amylose and amylopectin systems}

Yuyue Zhong ${ }^{1}$, Yu Tian ${ }^{1}$, Xingxun Liu $^{2}$, Li Ding ${ }^{1}$, Jacob Judas Kain Kirkensgaard ${ }^{3}$, Kim Hebelstrup ${ }^{4}$, Jean-Luc Putaux ${ }^{5}$, and Andreas Blennow ${ }^{1, *}$

${ }^{1}$ Department of Plant and Environmental Sciences, University of Copenhagen, DK-1871 Frederiksberg C, Denmark

${ }^{2}$ Lab of Food Soft Matter Structure and Advanced Manufacturing, College of Food Science and Engineering / Collaborative Innovation Center for Modern Grain Circulation and Safety / Key Laboratory of Grains and Oils Quality Control and Processing, Nanjing University of Finance and Economics, Nanjing, 210023, China

${ }^{3}$ Department of Food Science, University of Copenhagen, DK-1958 Frederiksberg C, Denmark

${ }^{4}$ Section for Crop Genetics and Biotechnology, Aarhus University, Flakkebjerg, Forsøgsvej 1, 4200 Slagelse, Denmark

${ }^{5}$ Univ. Grenoble Alpes, CNRS, CERMAV, F-38000 Grenoble, France

* corresponding author: abl@plen.ku.dk

Published in: Food Hydrocolloids 119 (2021), 106856

DOI: 10.1016/j.foodhyd.2021.106856 


\begin{abstract}
Pure granular amylose (AM) and pure granular amylopectin (waxy) starch (AP) granules have the high nutritional value in food industry. Effects of microwave treatment (400 W/g DW, 1$8 \mathrm{~min}$ ) on the structure and properties of transgenic AM granules and AP granules were investigated in direct comparison. Microwave treatment, especially during the first three minutes, decreased the molecular weight of molecules in both the AM and the AP samples. The crystallinity of AM starch initially increased from $15.6 \%$ to $20.6 \%$, which was associated with the formation of new $\mathrm{V}_{\mathrm{h}}$-type crystals. After that, crystallinity decreased alongside to $11.3 \%$ with the complete disruption of B-type crystals. In contrast, the crystallinity of AP starch initially decreased from $18.9 \%$ to $10.8 \%$ followed by an increase to $20.0 \%$. Upon prolonged treatment of AM granules, the resistant starch and water solubility was significantly increased. Our data demonstrate notable different microwave-dependent reorganization patterns for pure granular AM and AP molecules as native granular systems, which is helpful to the improvement of functionality of these two starches.
\end{abstract}

Keywords: microwave treatment, amylose, amylopectin, crystalline structure, digestibility 


\section{Introduction}

Starch is a natural biopolymer found as energy reserve in our most important crops including cereals, tubers, roots, fruits, and seeds, and has been applied in different industries, such as food, drug delivery, and composite biodegradable plastics. Starch has different levels of structure, including amylose and amylopectin molecules $(\sim 0.1 \mathrm{~nm}$ range), crystalline and amorphous lamellar structure $(\sim 10 \mathrm{~nm}$ range), alternating amorphous and semi-crystalline growth rings ( $\sim 0.1 \mu \mathrm{m}$ range) and starch granules (1-100 $\mu \mathrm{m}$ range) (Zhong et al., 2019). Native starch has limited industrial utilization due to a number of undesirable properties, such as water insolubility at room temperature, retrogradation and syneresis. Generally, physical/chemical/enzymatic modifications of starch improve important properties like suppressed or stimulated retrogradation and increased paste clarity and stability and thus is of major industrial interest within food, feed, paper, and textile applications (Blennow, 2018; Maniglia, Castanha, Le-Bail, Le-Bail, \& Augusto, 2020; Vanier, El Halal, Dias, \& da Rosa Zavareze, 2017).

Microwave treatment has gained in importance as an efficient processing protocol for clean starch modification due to its ability to achieve more uniform heating, safe handling, ease of operation, low maintenance and high efficiency in modifying starch structure to improve its functional properties (Chandrasekaran, Ramanathan, \& Basak, 2013; Yang, et al., 2017). However, the mechanisms of microwave-induced molecular and physical alterations are still obscure and await direct comparative testing, especially for pure granular AM and AP systems.

Microwave treatment, through its high-frequency electric fields, typically induces micro movements and frictions of starch molecules (Fan et al., 2013) thereby converting electromagnetic energy into thermal energy and generating concurrent internal and external heating (Galema, 1997). It has been reported that microwave treatment can increase the resistant starch (RS) content (Mutlu, Kahraman, \& Öztürk, 2017) and gelatinization temperature of normal starch (Yang et al., 2017), and decrease the viscosity of maize pure amylopectin (AP, so-called waxy maize starch) granules (Yang et al., 2017) by inducing the disruption and rearrangement of the starch molecules (Yang et al., 2017; Zhong et al., 2019). Existing data suggest that starch molecules located in amorphous regions of the starch granule were affected initially, followed by effects on the crystalline regions (Chandrasekaran et al., 2013; Yang et al., 2017).

High-amylose (HAM) starch has drawn attention mainly due to its high RS content and excellent mechanical properties and these starch types therefore attain high value in vastly 
different areas, such as for bioplastics films, coating and functional food products (Guan et al., 2011; Zhong et al., 2020). Just as for normal starch, long-term microwave treatment of HAM starch can increase its gelatinization transition temperatures and the gelatinization temperature range, decrease swelling power, water solubility, syneresis and gelatinization enthalpy (Luo, $\mathrm{He}, \mathrm{Fu}, \mathrm{Luo}, \& \mathrm{Gao}, 2006)$. Interestingly, the structural stability of HAM starch can be improved after only a rather short-time microwave treatment (400 $\mathrm{W} \mathrm{g}^{-1}, 1 \mathrm{~min}$ ), reflected as an increase in peak viscosity and RS content, which is suggested to be an effect of aggregation of cleaved AM chains (Zhong et al., 2019). With further treatment, the structural stability of the starch is decreased as indicated by a decrease in peak viscosity and RS content, which suggests major disordering of the crystalline regions (Zhong et al., 2019). Hence, by controlling the microwave treatment time and applied energy, the functionality of HAM starch can be altered correspondingly according to the requirements.

The structural and functional alterations of waxy starch (AP) (Yang et al., 2017), low-AM starch (Luo et al., 2006), and HAM starch (Zhong et al., 2019) resulting from microwave irradiation have been previously investigated. For AP maize starch granules, the process entailed an initial disruption of the amorphous regions followed by its destruction (Yang et al., 2017). However, the effect of microwave treatment of AM in its native, granular state remains to be investigated. Such data will gain understanding on how microwaves affect AM molecules in their pure granular state, which constitutes a much more dynamic, but also partly stable aggregated system, than AP. The recent staggering developments in crop bioengineering has now permitted the generation of very high AM contents (Blennow et al., 2013; Hebelstrup et al., 2015) and a pure AM barley mutant was previously generated by suppressing all starch branching enzymes (Blennow, et al., 2013; Carciofi, et al., 2012; Hebelstrup, Sagnelli, \& Blennow, 2015), providing the possibly to investigate the role of AM more precisely (Goldstein et al., 2016). AM chains are cleaved and aggregated during the microwave heating in HAM starch thereby increasing the granular stability (Zhong et al., 2019). We hypothesize that the aggregation level of AM molecules in a pure AM granular system is higher than that of HAM starch system, without the hindering effect of AP molecules. By this approach, the functionality (i.e., higher resistant starch content) of AM can be further improved.

We anticipate that pure amylose and pure amylopectin derived from engineered crops can be game changers for future demanding applications and hypothesized that such systems respond differently against microwave treatment. Therefore, we investigated the effects of such treatment at different time points (1-8 $\mathrm{min}$ ) on pure granular barley AM as compared to pure granular maize AP by collecting data at different structural levels, rheological properties and 
amylolytic digestibility. We chose waxy maize starch granules as the pure AP system since the effect of microwave treatment on this starch type is very well characterized (e.g. Yang et al., 2017, Luo, He, Fu, Luo, \& Gao, 2006). Pure AP starches have substantial similarity in structure across waxy barley and waxy wheat (Vamadevan and Bertoft, 2018). In contrast, the difference between waxy starch and high-amylose starch is more remarkable (Zhong et al., 2020). Our data provide fundamental and direct comparative information on how AM and AP in their native, granular system are differentially affected by microwave irradiation. Such information is helpful to understand the structural changes of AM and AP granular starches under microwave irradiation, thereby further improving industrial functionality of these two starch types.

\section{Materials and methods}

\subsection{Materials}

AP granules from maize (Zea maize) (provided by Sigma, St. Louis, MO, USA) and AM granules extracted from a transgenic barley line with all starch branching enzymes (SBEs) suppressed (Carciofi et al., 2012) were purified by alkaline method and used in this study. The purity of starches was tested by the total starch assay kit (Sigma-Aldrich), with the purity higher than 95\% (Table S1). The lipid content and protein content are both lower than $1 \%$. $\alpha-1,6-$ glucosidic acting debranching enzymes, isoamylase (E-ISAMY, $280 \mathrm{U} \mathrm{mL}^{-1}$ ), and pullulanase (E-PULKP, $650 \mathrm{U} \mathrm{mL}^{-1}$ ), were supplied from Megazyme (Ireland). Pancreatin (Cat. No. P7545) and amyloglucosidase (Cat. No. A7095) were from Sigma (St. Louis, MO, USA).

\subsection{Microwave treatment}

Short-term microwave treatment was performed as described (Zhong et al., 2019). Specifically, the moisture content of starches was measured by heating at $120^{\circ} \mathrm{C}$ for $48 \mathrm{~h}$. AM or AP (2.0 g, dry weight) was spread on glass petri dishes as a uniform layer, followed by injecting an appropriate amount of distilled water into the glass petri dishes by a syringe to increase the sample moisture content to $30 \%(\mathrm{w} / \mathrm{w})$ with $3 \mathrm{~h}$ slow stirring. The weight and moisture contents were specifically set at intermediate level for easily controlling the treatment process and the comparability with the reported HAM starch systems (Zhong et al., 2019). The

petri dishes were sealed and placed in the center of a microwave oven (frequency $2450 \mathrm{MHz}$, Amana Refrigeration Inc., IA, USA) with the output power of $800 \mathrm{~W}$, i.e., $400 \mathrm{~W} \mathrm{~g}^{-1} \mathrm{DW}$. Treatment was performed for 1, 2, 3, 4, 6, and 8 min and uniform treatment was secured by automatic rotation. The color gradually turned yellow from 4 min indication partial. The treated 
samples were collected and dried at $30{ }^{\circ} \mathrm{C}$ for $24 \mathrm{~h}$ prior to further analysis to decrease the humidity of samples to the similar level of native raw starches. According to the time (x) of microwave treatment, the samples were termed as APx or AMx. For each time point, six batches were prepared, and three of them were randomly selected, pooled and mixed.

\subsection{Size-exclusion chromatography (SEC) and iodine-binding capacity}

The molecular structure of both native and debranched samples was analyzed by a sizeexclusion chromatography - triple detector array SEC-TDA (Viscotek, Malvern, UK) instrument equipped with tandem GS-520HQ / GS-320HQ Shodex columns attached to a TDA302 detector array (Zhong et al., 2021). Samples (5 mg) were dissolved in $20 \mu \mathrm{L} 2 \mathrm{M}$ sodium hydroxide $(\mathrm{NaOH})$ in $4{ }^{\circ} \mathrm{C}$ overnight for gentle gelatinization of starch by alkaline, diluted to $5 \mathrm{mg} \mathrm{mL}^{-1}$ and incubated at $80{ }^{\circ} \mathrm{C}$ for $5 \mathrm{~h}$. The samples were diluted to $1 \mathrm{mg} \mathrm{min}^{-1}$, centrifuged at 20,000 $\mathrm{g}$ for $5 \mathrm{~min}$ and $50 \mu \mathrm{L}$ supernatant injected onto the SEC-TDA system. Elution was performed using ammonium formate $(10 \mathrm{mM})$ at a flow rate of $0.5 \mathrm{~mL} \mathrm{~min}^{-1}$ and column temperature of $60^{\circ} \mathrm{C}$. Debranching of gelatinized samples (AP and AM were gelatinized starch dispersion in screwed tubes by heating at $99{ }^{\circ} \mathrm{C}$ and $130{ }^{\circ} \mathrm{C}$ (with highpressure) for $1 \mathrm{~h}$, respectively) was performed by adding $2 \mu \mathrm{L}$ isoamylase and $2 \mu \mathrm{L}$ pullulanase and incubating $5 \mathrm{mg} / \mathrm{mL}$ in sodium acetate buffer ( $\mathrm{pH} 4.0$ ) at $40{ }^{\circ} \mathrm{C}$ for $3 \mathrm{~h}$. Complete debranching was verified by the point of insignificant increase in reducing ends (Donor \& Irwin, 1992). Samples were diluted to $1 \mathrm{mg} \mathrm{mL}^{-1}$ before injecting to the SEC-TDA system. Linear monodisperse pullulan standards (P50, P200, Sigma Aldrich) were used for instrument calibration and permit calculation the absolute molecular weight and hydrodynamic radii $\left(\mathrm{R}_{\mathrm{h}}\right)$ of the native samples. The iodine complexation of samples was analyzed using $5 \mathrm{mg}$ sample powder dissolved in $0.75 \mathrm{~mL}$ of $4 \mathrm{M} \mathrm{NaOH}$ under vigorous stirring overnight, where after $2.25 \mathrm{~mL}$ MilliQ water was added. Finally, $10 \mu \mathrm{L}$ sample was mixed with $200 \mu \mathrm{L}$ of 10 -times diluted Lugol solution $(\mathrm{pH}=2)$ before measuring the absorbance at 550 and $620 \mathrm{~nm}$ (Carciofi et al., 2012).

\subsection{High-performance anion exchange chromatography-pulsed amperometric detection (HPAEC-PAD)}

Enzymatic debranching was as described in section 2.3. AM or AP $\left(10 \mu \mathrm{L}, 5 \mathrm{mg} \mathrm{mL}^{-1}\right)$ was injected onto a CarboPac PA-200 column attached to an HPAEC-PAD (Dionex, Sunnyvale, CA, USA) system. Peak integration and detector response were performed as described (Blennow, Bay-Smidt, Wischmann, Olsen, \& Møller, 1998). 


\subsection{Wide-angle X-ray scattering (WAXS)}

Following conditioning of the samples at a humidity chamber with $90 \%$ relative humidity by saturated $\mathrm{KCl}$ for $72 \mathrm{~h}$, the samples were analyzed using a SAXSLab instrument (JJ-X-ray, Copenhagen, Denmark) equipped with a $100 \mathrm{XL}+$ microfocus sealed X-ray tube $\left(\mathrm{Cu}-\mathrm{K}_{\alpha}\right.$ radiation, Rigaku, The Woodlands Texas, USA) and a 2D $300 \mathrm{~K}$ Pilatus detector (Dectris Ltd, Baden, Switzerland) (Zhong, et al., 2021). The radially averaged intensity I is given as a function of the scattering angle $2 \theta$ in the angular range $5-30^{\circ}$ using $40 \mathrm{~mA}$ current, $40 \mathrm{kV}$ voltage, and $0.1542 \mathrm{~nm}$ wavelength $\mathrm{Cu} \mathrm{K} \alpha$ radiation. The relative crystallinity was calculated as described (Brückner 2000; Goldstein et al., 2016). The amorphous background scattering was estimated by a 30-cycles iterative smoothing algorithm (MATLAB, Natick, Massachusetts, USA), and the relative crystallinity was calculated:

\section{Relative Crystallinity $=$ Area of Peaks $/$ Total Area}

where the areas were numerically integrated using built in MATLAB functions (Brückner, 2000; Goldstein et al., 2017).

\subsection{Swelling power and water solubility}

Swelling power and water solubility were determined as described (Wang \& Copeland, 2012). AM or AP (40 mg mL-1 DW) was heated at $60{ }^{\circ} \mathrm{C}$ for $1 \mathrm{~h}$, followed by cooling to $20^{\circ} \mathrm{C}$ and centrifugation at $13,000 \mathrm{~g}$ for $20 \mathrm{~min}$. The supernatant was collected and dried at $120{ }^{\circ} \mathrm{C}$ for $24 \mathrm{~h}$, and the water solubility (\%) was calculated as percent of the weight of the dried supernatant of the original dry weight $(40 \mathrm{mg})$. Swelling power $(\mathrm{g} / \mathrm{g})$ was calculated from the ratio of the weight of the precipitate and the original weight of the sample.

\subsection{In vitro digestion}

The digestion of raw samples and retrograded samples (starch was gelatinized and stored at $4{ }^{\circ} \mathrm{C}$ for 1 day) was analyzed with minor modifications (Zhong et al., 2019). The gelatinization of AP and AM starches were conducted by heating at 99 and $130{ }^{\circ} \mathrm{C}$ for $1 \mathrm{~h}$, respectively. AM or AP $(100 \mathrm{mg}), 5 \mathrm{~mL}$ water and $10 \mathrm{~mL}$ sodium acetate buffer $(0.1 \mathrm{M}, \mathrm{pH}$ 5.2) were mixed by vortexing for $5 \mathrm{~min}$, followed by equilibrating the mixture at $37^{\circ} \mathrm{C}$ for 30 min. The reaction was initiated by adding $2.5 \mathrm{~mL}$ sodium acetate buffer containing $18.75 \mathrm{mg}$ pancreatin and $13.4 \mu \mathrm{L}$ amyloglucosidase into the mixture. Aliquots $(0.1 \mathrm{~mL})$ were withdrawn at 20 and $120 \mathrm{~min}$ and the reaction terminated by adding $1 \mathrm{~mL} \mathrm{95 \%} \mathrm{ethanol.} \mathrm{Released} \mathrm{glucose}$ content was analyzed by the Megazyme GOPOD kit. The samples digested in 0-20 min was 
defined as rapidly digested starch (RDS), and the starch digested in 20-120 min was defined as slowly digested starch (SDS). The remaining residues were subtracted from RDS and SDS and defined as RS.

\subsection{Rheology}

The dynamic rheological analysis was analyzed from gelatinized $(8 \%, \mathrm{w} / \mathrm{v})$ starch gels by a Discovery HR-3 Rheometer (TA Instruments, New Castle, UK) at $25{ }^{\circ} \mathrm{C}$. The gelatinization was performed as mentioned in section 2.3. Frequency sweeps were carried out from 0.01-100 Hz. Rheological parameters including storage modulus $\left(\mathrm{G}^{\prime}\right)$, loss modulus $\left(\mathrm{G}^{\prime \prime}\right)$, loss tangent $\left(\mathrm{G}^{\prime} / \mathrm{G}^{\prime \prime}, \tan \delta\right)$, and the modulus of complex viscosity $\left(\eta^{*}\right)$ were calculated.

\subsection{Statistical analysis}

WAXS analyses were performed once for each sample and all other experiments were performed triplicate. Differences were analyzed using one-way analyses of variance (ANOVAs) followed by Duncan's test $(\mathrm{p}<0.05)$ in SPSS 18.0 (SPSS Inc., Chicago, IL, USA).

\section{Results and discussion}

\subsection{Microwave-assisted molecular degradation}

The molecular size distribution as analyzed by SEC-TDA of the native (not debranched) samples (Fig. 1A) showed a shift of retention volume of both the AP and the AM to higher values with the increased microwave treatment time, indicating microwave-induced molecular scission of both these types of glucan. The molecular weight $(\mathrm{Mw})$ and molecular size $\left(\mathrm{R}_{\mathrm{h}}\right)$ of AP and AM both showed sigmoidal decays and for both AP and AM the sharp drop occurred between 3 and 4 min (Table 1). The AP sample also showed a similar decrease in the iodine complexation ratio $(620 \mathrm{~nm} / 550 \mathrm{~nm})$ (Table 1), demonstrating that the iodine complexation of AP and its $\mathrm{Mw}$ concomitantly decreased. In contrast, the iodine complexation of AM decreased slowly during the entire treatment period, indicating that the decrease in Mw of AM had less effect on the formation of iodine complexation. The chain length distribution (CLD) of the side chains analyzed by SEC of debranched samples (Fig. 1B), demonstrated that the CLDs of AP after debranching only had a minor decrease, whereas CLDs of the AM samples displayed a more drastic shift of the peak position to higher elution volumes. 

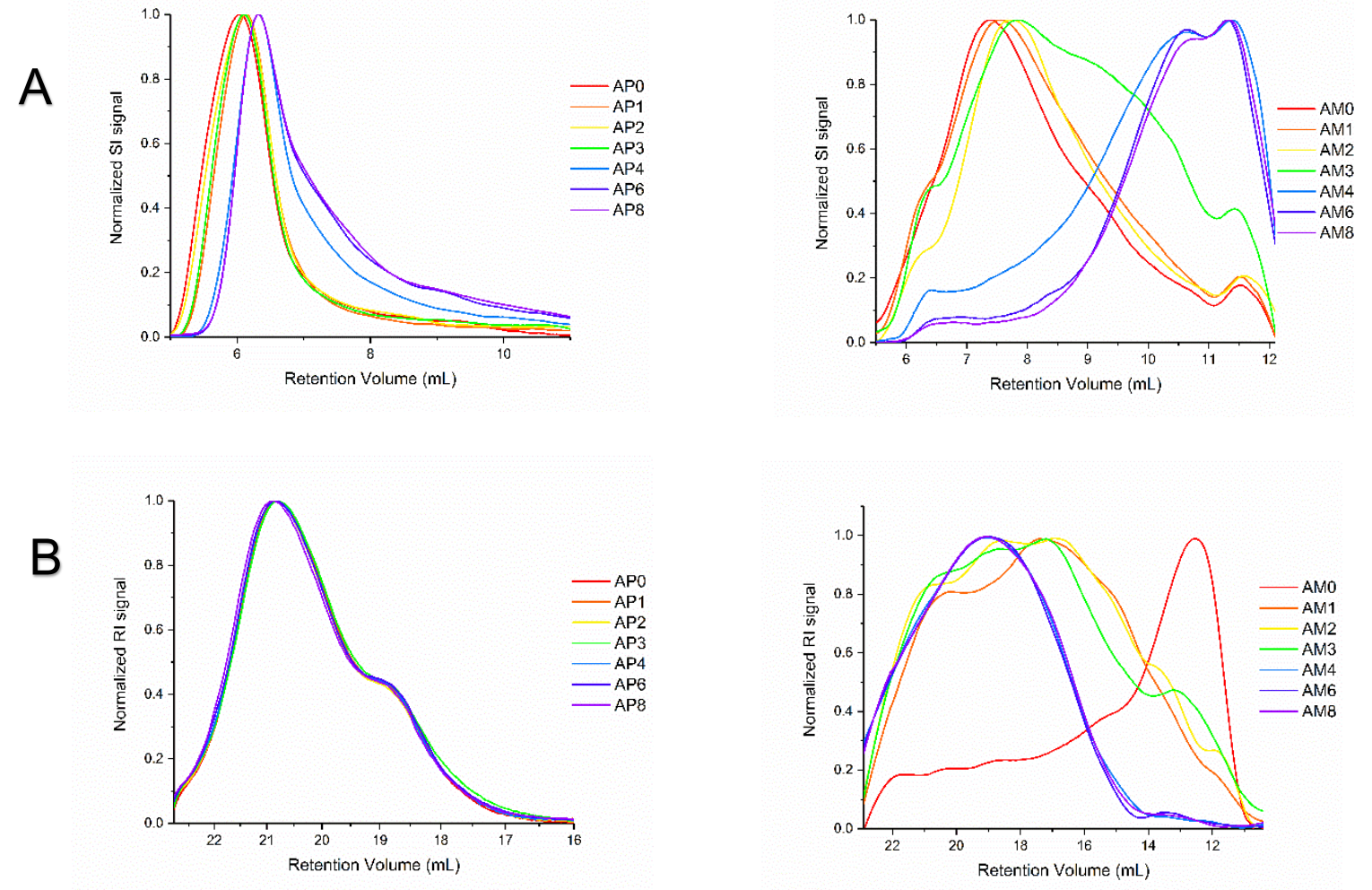

Figure 1. SEC profiles of native AP and AM microwave treated for different time periods (A), and SEC profiles of debranched samples (B). Abbreviations as in the main text.

Table 1. Molecular weight $(\mathrm{Mw})$, hydrodynamic radii $\left(\mathrm{R}_{\mathrm{h}}\right)$, and iodine-binding capacity (absorbance at $620 \mathrm{~nm} / 550 \mathrm{~nm}$ ) of microwave treated AM and AP $(\mathrm{n}=2)$. All data are means \pm standard deviation. Values with different letters in the same column are significantly different at $p<0.05$.

AP

AM

Treatment time (min)

$\mathrm{Mw} \times 10^{7} \quad \mathrm{R}_{\mathrm{h}}(\mathrm{nm})$

Iodine binding

capacity

$\mathrm{Mw} \times 10^{7}$

$\mathrm{R}_{\mathrm{h}}(\mathrm{nm})$

Iodine binding capacity

\begin{tabular}{ccccccc}
\hline 0 & $17.7 \pm 0.9^{\mathrm{a}}$ & $85.9 \pm 6.9^{\mathrm{a}}$ & $1.27 \pm 0.01^{\mathrm{a}}$ & $9.6 \pm 1.2^{\mathrm{a}}$ & $30.5 \pm 1.2^{\mathrm{a}}$ & $0.65 \pm 0.00^{\mathrm{a}}$ \\
1 & $17.3 \pm 0.9^{\mathrm{a}}$ & $80.3 \pm 6.3^{\mathrm{b}}$ & $1.25 \pm 0.02^{\mathrm{ab}}$ & $8.4 \pm 1.3^{\mathrm{b}}$ & $27.5 \pm 1.0^{\mathrm{b}}$ & $0.65 \pm 0.00^{\mathrm{a}}$ \\
2 & $12.6 \pm 0.9^{\mathrm{b}}$ & $72.4 \pm 3.4^{\mathrm{c}}$ & $1.22 \pm 0.02^{\mathrm{b}}$ & $5.9 \pm 0.4^{\mathrm{c}}$ & $26.8 \pm 0.3^{\mathrm{bc}}$ & $0.64 \pm 0.00^{\mathrm{b}}$ \\
3 & $1.7 \pm 0.0^{\mathrm{c}}$ & $35.7 \pm 1.4^{\mathrm{d}}$ & $1.14 \pm 0.01^{\mathrm{c}}$ & $3.0 \pm 0.1^{\mathrm{d}}$ & $25.9 \pm 0.7^{\mathrm{c}}$ & $0.64 \pm 0.00^{\mathrm{b}}$ \\
4 & $0.9 \pm 0.1^{\mathrm{d}}$ & $34.1 \pm 0.2^{\mathrm{e}}$ & $0.80 \pm 0.01^{\mathrm{d}}$ & $0.5 \pm 0.1^{\mathrm{e}}$ & $13.9 \pm 0.4^{\mathrm{d}}$ & $0.64 \pm 0.00^{\mathrm{b}}$ \\
6 & $0.9 \pm 0.1^{\mathrm{d}}$ & $34.7 \pm 0.1^{\mathrm{e}}$ & $0.60 \pm 0.02^{\mathrm{e}}$ & $0.1 \pm 0.0^{\mathrm{f}}$ & $9.6 \pm 0.0^{\mathrm{e}}$ & $0.63 \pm 0.00^{\mathrm{c}}$ \\
8 & $0.8 \pm 0.0^{\mathrm{d}}$ & $31.9 \pm 0.6^{\mathrm{f}}$ & $0.59 \pm 0.01^{\mathrm{e}}$ & $0.1 \pm 0.0^{\mathrm{f}}$ & $8.3 \pm 0.0^{\mathrm{f}}$ & $0.63 \pm 0.00^{\mathrm{c}}$ \\
\hline
\end{tabular}




\subsection{Chain length distribution (CLD) of $A P$ and AM side chains}

HPAEC-PAD data (Fig. 2A) revealed further chain distributional details. Specifically, chains with DP $>16$ were degraded to shorter chains with $\mathrm{DP}<16$, peaking at DP 11 produced after 1 min microwave treatment, whereas no more significant variations of AP CLD was found with further treatment (Fig. 2B). AM also exhibited some side chains with the peak at DP 12 after debranching, showing that some molecules in AM had partial branches (Fig. 2A). AM granules are generated by suppressing all SBEs during starch biosynthesis pathways (Carciofi, et al., 2012), and 'amylose-like' material is produced during the amylopectin biosynthesis (Zhong, Liu, Qu, Li, Blennow, \& Liu, 2020). We suggest that the branches in AM originate from the 'amylose-like' material. It is clear that, with increased microwave treatment time, the range of CLD in AM became narrower starting at DP 1-60 ending at DP 1-30, which implies preferential degradation of long side chains. For AM, microwave treatment led to significant increases in the relative content of maltooligosaccharides, i.e. chains with DP $<10$ (Fig. 2B).
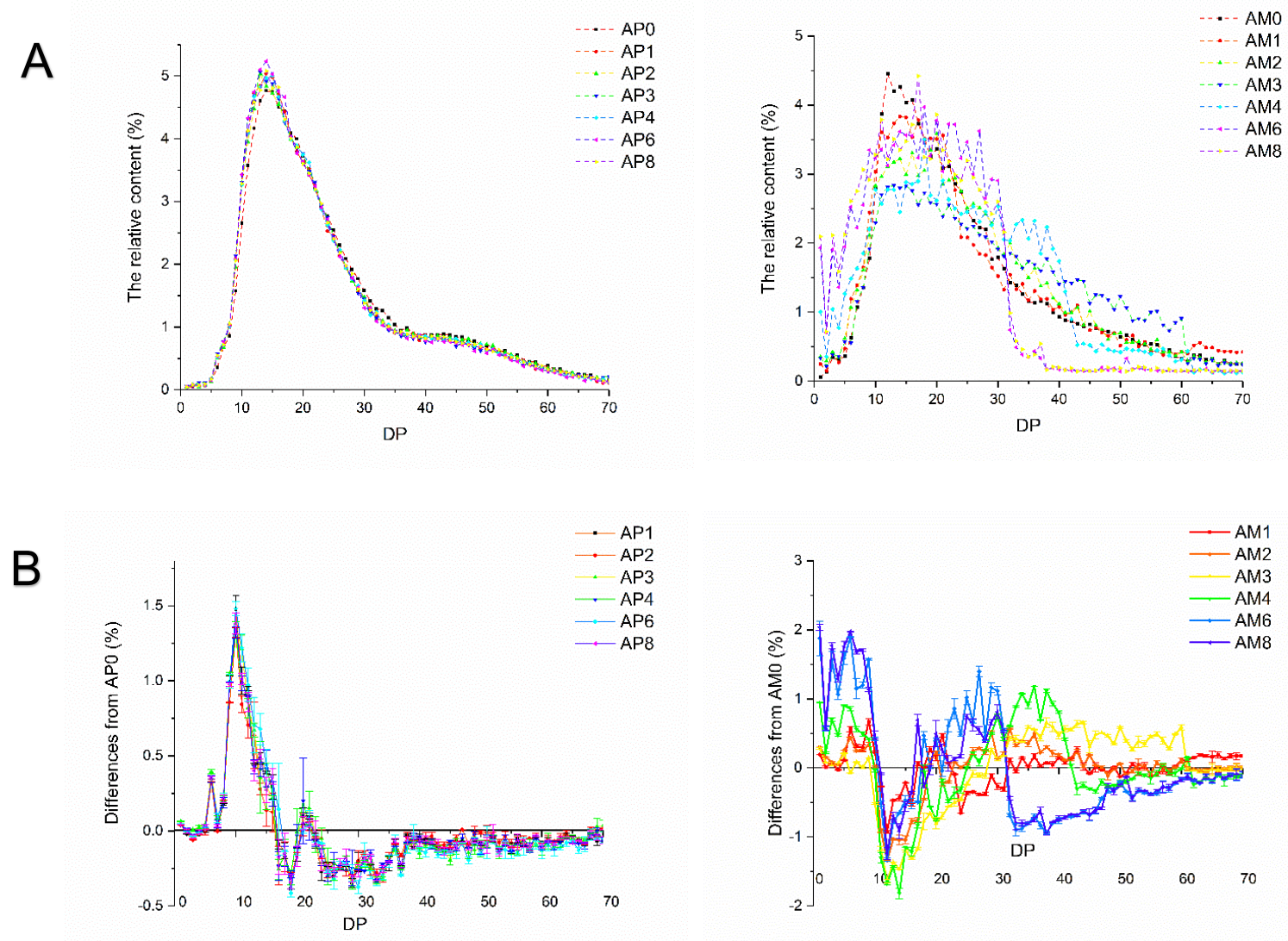

Figure 2. Chain length distribution profiles as determined by HPAEC of debranched AP and AM microwave treated for different time periods (A), and AP chain length distribution difference plots from corresponding controls AP0 and AM0 (B), respectively. Abbreviations as in Fig. 1. 


\subsection{Crystalline dynamics of the microwave treated samples}

The change in crystalline allomorphs as deduced from WAXS data (Fig. 3) showed that all AP granules exhibited the typical signature of the A-type crystalline allomorph with two strong peaks at $2 \theta$ around 15 and $23^{\circ}$, and an unresolved doublet at $2 \theta=17$ and $18^{\circ}$ (Cheetham $\&$ Tao, 1998). Microwave treatment resulted in an initial decrease in intensity of all reflections, especially for the peak at $2 \theta=23^{\circ}$ in samples $0-3 \mathrm{~min}$, revealing damage in the crystallinity regions, which has been documented also for normal starch granules (Oyeyinka, Umaru, Olatunde, \& Joseph, 2019). Interestingly, we found that the intensity of the AP granular peaks increased again upon further treatment (4-8 $\mathrm{min}$ ) which is supposedly associated with the strengthened reaggregation capacity of degraded AP molecules (Zhong et al., 2021). In contrast, the initial AM granules displayed a combination of B-type (at $2 \theta=17,22$, and $26^{\circ}$ ) and $\mathrm{V}_{\mathrm{h}}$-type (at $2 \theta=8,13,15$, and $20^{\circ}$ ) allomorph (Fig. 3), as reported (Carciofi et al., 2012). Increased treatment time from 0 to 2 min weakened the intensities of peaks at $2 \theta$ of 22 and $26^{\circ}$ and increased the intensity of peak at $2 \theta$ of $20^{\circ}$, which demonstrates the disruption of the B-type allomorph and concomitant formation of the $\mathrm{V}_{\mathrm{h}}$-type allomorph by amylose and endogenous uncomplexed lipids. However, further treatment (2-8 $\mathrm{min})$, resulted in decreased intensity of the $\mathrm{V}_{\mathrm{h}}$-type crystalline allomorph, reflecting a destruction of this allomorph possibly due to the degradation of amylose or the degradation of the lipids which in turn induce a destabilization of the V-type allomorph.

Correspondingly, for AP we observed that the relative crystallinity decreased initially (0-3 $\mathrm{min}$ ), followed by an increase (3-8 $\mathrm{min}$ ) with increased microwave treatment. By contrast, the relative crystallinity of AM granules initially increased (0-2 $\mathrm{min})$ and then decreased (2-8 $\mathrm{min})$. Although the microwave treatments induced molecular degradation in both AP and AM granules, significant differences between these two polysaccharides were identified. AP molecules form ordered crystalline structures due to the ability of its short side chains to form double helices that interact in a parallel manner to form $9 \mathrm{~nm}$ repeated lamellar structures in the starch granule (Bertoft, 2017). Short-time microwave-assisted degradation of AP granules, i.e. 1-3 min, possibly induced partial collapse of these crystalline lamellae and the unwinding of double helices. However, longer microwave treatment of AP granules further degraded this type of glucan to small molecules, which became more flexible. Hence, the high-frequency microwave electric fields can lead to micro-movements of these degraded AP molecules as suggested (Fan et al., 2013) resulting in molecular reorganization of double helices. In contrast, pure AM granules are not capable to build such ordered structures, as evident from the irregular morphology and disordered lamellar structure of AM granules (Carciofi et al., 2012; Shaik et 
al., 2014, 2016; Goldstein et al., 2016). However, the low molecular size of AM granules as compared to AP granules makes it more mobile, and thus AM molecules can form new crystals in the first 2 min through microwave-assisted molecular movements. It should be noted that the original B-type crystals were also disrupted during this process. A reorganization from the original weak $\mathrm{V}_{\mathrm{h}}$ /B-type to a stronger, mainly B-type, allomorph was identified in acidhydrolyzed (lintner) starch samples (Goldstein et al., 2016). Further degradation of AM molecules was possibly related to the production of very small maltooligosaccharides that potentially prevent the formation of large crystalline structures (Goldstein et al., 2016).

The effects of microwave treatment on altering the crystalline allomorph have also been found for the potato starch system (Lewandowicz, Fornal, \& Walkowski, 1997) and for amylomaize V (Luo, He, Xiong, Luo, \& Gao, 2006). In these cases, the WAXS profile changed from B-type to A-type, due to the vaporization of the partial water molecules in the central channel of the B-unit cell and subsequent reorganization of the water molecules (Braşoveanu \& Nemţanu, 2014). However, no such transformation was found in microwave treated A-type starch granules, like waxy and normal maize starches (Luo, et al., 2006; Yang, et al., 2017) and normal wheat starch (Lewandowicz, Jankowski, \& Fornal, 2000). Hence, microwave treatment has only the capability to induce a conversion from B- to A-type and not vice versa except after complete dissolution of amylose (Nishiyama et al., 2010).

\subsection{Swelling power and water solubility}

Increased treatment time suppressed swelling power for both AP and AM (Fig. 4), which is consistent with previous studies on natural (mixed AM/AP) starch samples (Oyeyinka et al., 2019; Zeng et al., 2016). It has been suggested that the transformation of crystalline type and decreased granular crystallinity were the main reason for the decreased swelling power of microwave treated starch (Luo et al., 2006; Oyeyinka et al., 2019). However, the WAXS profiles show that the crystalline pattern of AP samples was not changed by the treatment and the crystallinity was increased in the $3-8$ min period, and thus the decreased swelling power observed for AP was likely attributed to other effects. We therefore suggest that decreased swelling power was mainly caused by molecular degradation as suggested before (Keeratiburana, Hansen, Soontaranon, Blennow, \& Tongta, 2020; Zhong et al., 2021). After microwave treatment, molecules in AM and AP samples were cleaved into different smaller segments, which readily aggregate, decreasing space to bind water. In comparison to AP, AM had lower swelling power all the time points. Such an effect can possibly also originate from 
the formation of a network surrounding the swollen granules formed by leached AM molecules during heating inhibiting the further swelling (Tester \& Morrison, 1990). Therefore, microwave treated AP and AM can have high potential in food products that require low swelling such as starch noodles (Lii \& Chang, 1991).
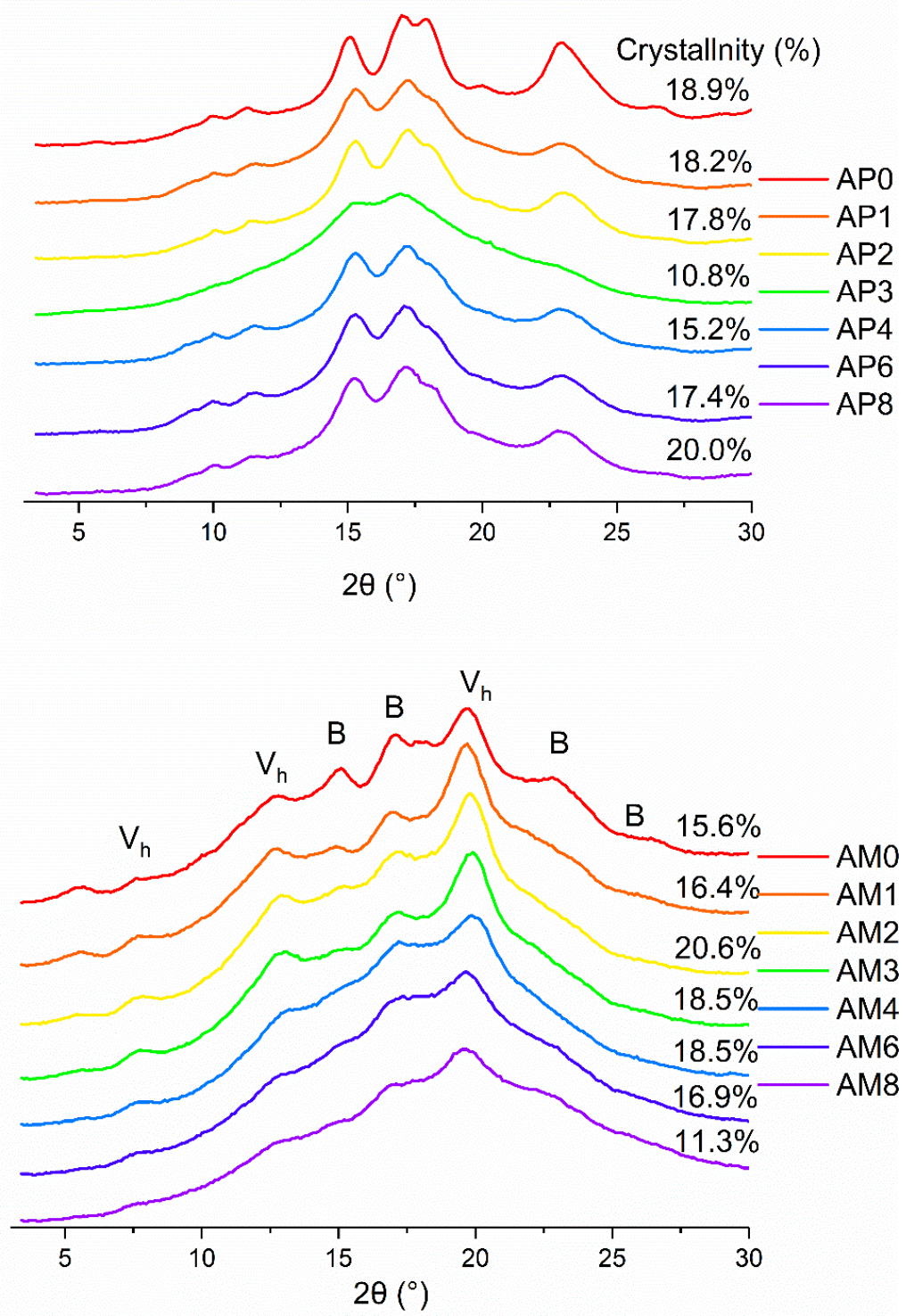

Figure 3. Effects of crystallinity and crystalline allomorphs of AP and AM as determined by WAXS. Abbreviations as in Fig. 1.

Native AM had lower water solubility than native AP (Fig. 4). Microwave treatment has been documented to generate soluble parts mainly composed of leached AP and short AM chains (Green, Blankenhorn, \& Hart, 1975; Jackson, Waniska, \& Rooney, 1989). The AM sample contained low amounts of short AM chains (Fig. 1A) leading to low water solubility (Fig. 4). However, microwave treatment led to increased water solubility in both AM and AP 
by molecular degradation producing small soluble maltooligosaccharides. This increase was notably higher in AM than in AP (Fig. 4), an effect likely due to the higher degradation degree of AM samples (Fig. 1A) leading to leakage (Green et al., 1975; Jackson et al., 1989).

Our data can be compared to the minor effects in swelling power and water solubility found in maize starches with different AM contents after microwave treatment when using much lower effects, $1 \mathrm{~W} \mathrm{~g}^{-1}$, but somewhat longer treatment time of $20 \mathrm{~min}$ (Luo, et al., 2010). Such treatment can be expected to have much lower degradation levels in comparison to our study, which was also observed.

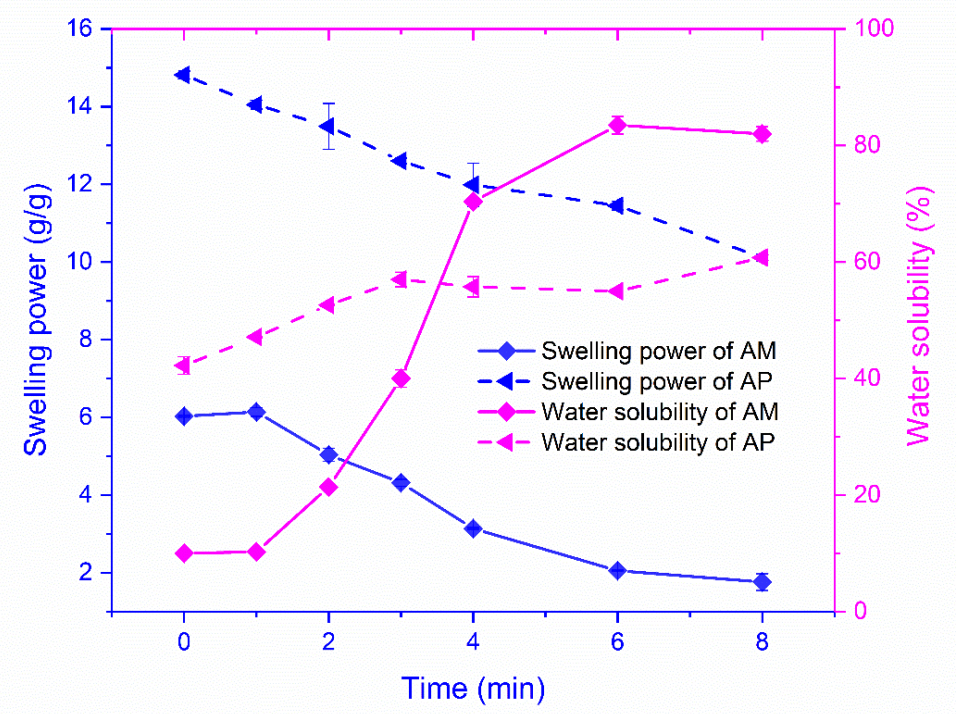

Figure 4. Swelling power and water solubility of AP and AM microwave-treated for different time periods.

\subsection{Amylolytic digestibility}

For granular AP, up to 3 min of treatment resulted in increased RDS content and decreased SDS and RS contents (Table 2), likely related to damage of crystalline granule regions (section 3.3), which can increase their enzymatic susceptibility. This effect is in agreement with previous data (Emami, Perera, Meda, \& Tyler, 2012). However, continued treatment increased the amylolytic resistance, i.e., the RDS content decreased, while the SDS content recovered to some degree (Table 2), which likely is an effect of the aggregation of AP fragments forming new crystals (Fig. 3). Starch is an important ingredient in food industry, and most starch-based foods, including bread, pasta and noodles, are stored for longer periods before selling, which affects the quality of the product, for example staling of bread. Hence, how structure and nutrition change during staling is important. Due to that starch-based foods are normally eaten in two days by consumers, we set a one-day retrogradation experiment. The degree of 
digestibility of retrograded starch is mainly related to differential arrangement of starch chains. Interestingly, our data showed that, for AP, the RS content increased within the first 3 min of treatment, followed by a reduction from the fourth min and onwards. These data indicate that, the low levels of AP molecular degradation can accelerate the reorganization of AP molecules and the formation of aggregated double-helical structures, possibly by decreasing the degree of branching, increasing the amounts and improving the rearrangement of linear segments (Zeng et al, 2016; Yang et al., 2017), in agreement with the previous findings (Zeng et al., 2016). Our data suggest that further degradation of AP did not result in additional reassociation of chains, possibly due to the weak association capacity of the shorter linear segments in these samples.

For granular AM, although new $\mathrm{V}_{\mathrm{h}}$-type crystals were formed during the disruption of B-type crystals during the first two minutes of treatment, it seems that damage of the crystalline regions still resulted in a loss of structural stability and disordering of the granules, thereby increasing its amylolytic susceptibility, as demonstrated by increased RDS and decreased SDS and RS (Table 2). With further microwave treatment, RDS content dropped and RS content rapidly increased, i.e., the amylolytic resistance increased. Such increase in RS was possibly attributed to the aggregation of highly mobile, small, hydrated AM molecules. Although most crystals were disrupted, the remaining residues formed by such small AM molecules were highly resistant, possibly due to their smaller surface area. Hence, our data suggest that the digestibility of AM granules is not directly associated with the crystallinity or the amounts of $\mathrm{V}_{\mathrm{h}}$-type crystals but more likely with the molecular weight and re-association capacity of starch molecules. Microwave-treated AM granules subsequently subjected to hydrothermal treatment and retrogradation had limited effects on the contents of RDS, SDS, and RS for the mildly (4 min) microwave-treated granules showing that the degradation level observed during this period had an insignificant effect on reorganization and degradability of AM (Table 3). However, from the fourth minute, the RS content increased dramatically and RDS and SDS contents decreased indicating that AM molecules rearranged more efficiently with decreased molecular size.

Hence, we found that in a microwave-heated native granular system, both AM and AP underwent an initial increase in amylolytic susceptibility (RDS) whereafter it decreased down to the level of native starch (AM) or slightly above this level (AP). Such increase in amylolytic susceptibility is related to the erosion of granular structure (Zhang, Chen, Liu, \& Wang, 2010). However, further microwave treatment increased the enzymatic resistance of both AM and AP. Such an effect is supposedly due to further destruction of the crystalline structures providing increased flexibility for mobility and re-association of amylose and amylopectin molecules in 
the granules (Zhong et al., 2019). As expected, AM granules showed a higher amylolytic resistance (high RS) than AP (high SDS) at this stage, due to the stronger re-association capacity of amylose molecules than amylopectin molecules (Zeng et al., 2016). The effect of microwave treatment on amylolytic resistance of retrograded AP and AM was different. Initially the enzymatic resistance of AP increased due to the degradation of amylopectin molecules (Table 3) which possibly resulted in the decrease of branching degree and the increase of linear segments (Yang et al., 2017; Zeng et al., 2016). However, our data show that a further treatment resulted in decreased RS content (Table 3), implying that the low capacity of smaller amylopectin segments to reassociate and form complexes with low amylolytic resistance. Instead, for AM, the RS content started to increase from the sixth minutes when the Mw of AM molecules was sufficiently small to allow for reorganization of the chains.

Table 2. In vitro digestion parameters of native AP and AM treated with microwave irradiation for different time periods $(\mathrm{n}=2)$. All data are means \pm standard deviation. Values with different letters in the same column are significantly different at $p<0.05$.

AP

$\mathrm{AM}$

\begin{tabular}{|c|c|c|c|c|c|c|}
\hline $\begin{array}{l}\text { Treatment time } \\
\qquad(\min )\end{array}$ & RDS (\%) & $\operatorname{SDS}(\%)$ & $\mathrm{RS}(\%)$ & RDS (\%) & $\operatorname{SDS}(\%)$ & $\mathrm{RS}(\%)$ \\
\hline 0 & $44.7 \pm 1.5^{\mathrm{f}}$ & $25.3 \pm 0.2^{b}$ & $30.0 \pm 1.2^{\mathrm{a}}$ & $32.2 \pm 0.7^{\mathrm{c}}$ & $29.9 \pm 0.5^{\mathrm{a}}$ & $37.9 \pm 1.2^{\mathrm{d}}$ \\
\hline 1 & $52.4 \pm 0.3^{\mathrm{e}}$ & $24.6 \pm 1.0^{\mathrm{c}}$ & $22.9 \pm 1.4^{b}$ & $42.0 \pm 0.9^{b}$ & $22.2 \pm 0.7^{\mathrm{b}}$ & $35.8 \pm 0.3^{\mathrm{e}}$ \\
\hline 2 & $57.2 \pm 1.1^{\mathrm{d}}$ & $23.4 \pm 0.7^{\mathrm{d}}$ & $19.4 \pm 1.7^{\mathrm{c}}$ & $48.7 \pm 1.1^{\mathrm{a}}$ & $22.0 \pm 0.7^{b}$ & $29.2 \pm 0.4^{\mathrm{f}}$ \\
\hline 3 & $66.6 \pm 1.0^{\mathrm{a}}$ & $13.5 \pm 0.7^{\mathrm{f}}$ & $19.9 \pm 1.9^{\mathrm{c}}$ & $47.4 \pm 1.1^{\mathrm{a}}$ & $22.6 \pm 0.5^{b}$ & $30.0 \pm 1.6^{\mathrm{f}}$ \\
\hline 4 & $62.5 \pm 0.5^{b}$ & $12.9 \pm 1.1^{\mathrm{g}}$ & $24.7 \pm 1.5^{\mathrm{b}}$ & $41.7 \pm 0.1^{\mathrm{b}}$ & $5.7 \pm 1.2^{\mathrm{c}}$ & $52.6 \pm 1.0^{c}$ \\
\hline 6 & $60.0 \pm 0.4^{\mathrm{c}}$ & $18.1 \pm 1.5^{\mathrm{e}}$ & $21.9 \pm 1.1^{\mathrm{b}}$ & $33.1 \pm 0.6^{\mathrm{c}}$ & $1.0 \pm 0.0^{\mathrm{e}}$ & $65.9 \pm 0.6^{\mathrm{b}}$ \\
\hline 8 & $56.7 \pm 0.1^{\mathrm{d}}$ & $21.3 \pm 1.6^{\mathrm{a}}$ & $22.0 \pm 1.7^{\mathrm{d}}$ & $29.6 \pm 0.8^{d}$ & $2.6 \pm 0.7^{\mathrm{d}}$ & $67.9 \pm 0.1^{\mathrm{a}}$ \\
\hline
\end{tabular}

\subsection{Rheological characteristics}

The rheological behavior of starch gels is dependent on the nature of soluble and reassociated molecules, as starch granules are fully disrupted following previous heating. The rheology of AP was not altered by mild (1-2 min) microwave treatment, i.e., all rheological parameters including storage modulus $\left(\mathrm{G}^{\prime}\right)$, loss modulus $\left(\mathrm{G}^{\prime \prime}\right)$, loss tangent $\left(\mathrm{G}^{\prime} / \mathrm{G}^{\prime \prime}, \tan \delta\right)$, and the modulus of complex viscosity $\left(\eta^{*}\right)$ for AP0, AP1 and AP2 were similar (Fig. 6). With further treatment, $G^{\prime}, G^{\prime \prime}$, and $\eta^{*}$ of AP started to decline, reflecting a general decrease of the strengths of the AP gels (Franck, 2004; Sun, Sun, Wang, Sánchez-Soto, \& Schiraldi, 2018). Samples treated for 3-4 min exhibited higher $\tan \delta$ than the original granules, indicating the 
formation of a plastic gel system (Franck, 2004; Sun, et al., 2018). Although 5-6 min of microwave treatment showed low $\tan \delta$ at low frequency, they had the highest increase in $\tan \delta$ with increased frequency, hence showing the strongest deformability of the AP granules. Therefore, molecular degradation of AP by microwave irradiation decreased the gel strength, but increased plastic behavior and deformability at longer treatment times.

Table 3 In vitro digestion parameters of retrograded AP and AM treated with microwave irradiation for different time periods $(\mathrm{n}=2)$. All data are means \pm standard deviation. Values with different letters in the same column are significantly different at $p<0.05$.

\begin{tabular}{|c|c|c|c|c|c|c|}
\hline \multirow{2}{*}{$\begin{array}{l}\text { Treatment time } \\
\quad(\min )\end{array}$} & \multicolumn{3}{|c|}{ AP } & \multicolumn{3}{|c|}{$\mathrm{AM}$} \\
\hline & RDS (\%) & SDS(\%) & $\mathrm{RS}(\%)$ & RDS (\%) & $\operatorname{SDS}(\%)$ & $\mathrm{RS}(\%)$ \\
\hline 0 & $56.8 \pm 0.1^{\mathrm{b}}$ & $30.5 \pm 0.2^{b}$ & $12.8 \pm 0.3^{\mathrm{e}}$ & $19.4 \pm 0.2^{\mathrm{c}}$ & $35.8 \pm 0.9^{\mathrm{a}}$ & $44.8 \pm 1.1^{\mathrm{c}}$ \\
\hline 1 & $62.0 \pm 0.4^{\mathrm{a}}$ & $20.7 \pm 0.2^{\mathrm{e}}$ & $17.3 \pm 0.6^{\mathrm{d}}$ & $17.2 \pm 0.0^{\mathrm{d}}$ & $36.4 \pm 1.1^{\mathrm{a}}$ & $46.3 \pm 1.1^{\mathrm{c}}$ \\
\hline 2 & $55.8 \pm 0.6^{\mathrm{c}}$ & $23.7 \pm 0.2^{\mathrm{c}}$ & $20.5 \pm 0.8^{c}$ & $19.6 \pm 0.3^{\mathrm{c}}$ & $33.3 \pm 0.6^{\mathrm{b}}$ & $47.1 \pm 0.9^{\mathrm{c}}$ \\
\hline 3 & $53.1 \pm 0.5^{\mathrm{d}}$ & $21.8 \pm 0.2^{\mathrm{d}}$ & $25.1 \pm 0.3^{\mathrm{a}}$ & $22.5 \pm 0.2^{\mathrm{a}}$ & $33.5 \pm 0.7^{b}$ & $44.0 \pm 0.9^{\mathrm{c}}$ \\
\hline 4 & $52.8 \pm 0.3^{\mathrm{d}}$ & $24.2 \pm 0.7^{\mathrm{c}}$ & $23.0 \pm .04^{\mathrm{b}}$ & $21.1 \pm 0.3^{b}$ & $30.2 \pm 0.2^{\mathrm{c}}$ & $48.8 \pm 0.6^{\mathrm{c}}$ \\
\hline 6 & $57.7 \pm 0.2^{\mathrm{b}}$ & $20.7 \pm 0.2^{\mathrm{e}}$ & $21.6 \pm 0.4^{\mathrm{c}}$ & $13.5 \pm 0.2 \mathrm{e}$ & $22.5 \pm 0.4^{\mathrm{e}}$ & $64.0 \pm 0.6^{b}$ \\
\hline 8 & $43.5 \pm 0.3^{\mathrm{e}}$ & $44.1 \pm 0.4^{\mathrm{a}}$ & $12.3 \pm 0.0^{\mathrm{e}}$ & $6.3 \pm 0.1^{\mathrm{f}}$ & $26.5 \pm 0.2^{\mathrm{d}}$ & $67.0 \pm 0.3^{\mathrm{a}}$ \\
\hline
\end{tabular}

The $\mathrm{G}^{\prime}$ of the AM gels initially increased (Fig. 5), showing that microwave irradiation can also increase the strengths of $\mathrm{AM}$ gels, although $\mathrm{G}^{\prime}$ started to decrease with further treatment, possibly due to the weak capacity of highly degraded AM molecules on forming gel network. Treatment for 2 and 3 min resulted in higher $\mathrm{G}^{\prime \prime}$ than the original and mildly treated granules indicating that longer treatment generated viscoelastic systems with higher energy dissipation (viscosity or plasticity) under deformation. However, $\mathrm{G}^{\prime \prime}$ decreased below the value of the original sample on extensive treatment (6 and 8 min treatments) demonstrating very low viscosity. The value of $\tan \delta$ was similar in all AM samples, except for the 8 min sample, suggesting that microwave irradiation had limited effect on the elastic and plastic behavior of the AM gels. Just as for the $\mathrm{G}^{\prime}$ and $\mathrm{G}^{\prime \prime}$, the complex modulus $\eta^{*}$ increased initially (0-3 min) and then decreased with increased (3-8 min) microwave treatment. Hence, the strength of AM gels can be increased by 1-2 min microwave treatment, while longer treatment times continuously decreased the strengths of AM gels. 

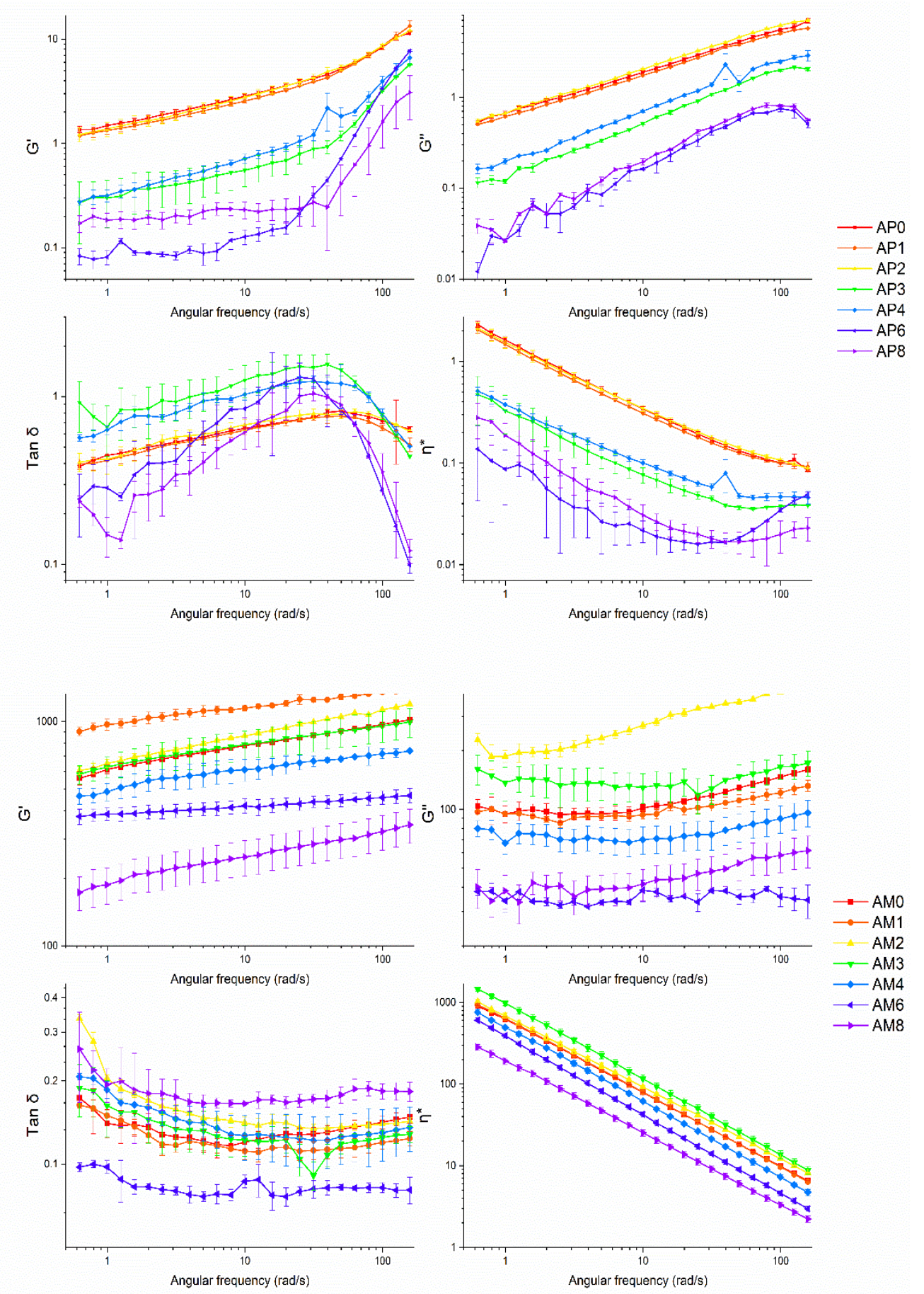

Figure 5. Rheological characteristics of AP and AM treated for different time periods. Abbreviations as in Fig. 1.

\subsection{The comparison of the effects of microwave treatment on the structure of AP and AM}

Our data for pure granular AM and AP systems suggest that the main structural effects of short-term $(1 \mathrm{~min})$ microwave irradiation at moderate $\left(400 \mathrm{~W} \mathrm{~g}^{-1}\right)$ regimes were on the crystalline parts for both systems (Fig. 6). For a granular AP system treated at relatively low $\left(160 \mathrm{~W} \mathrm{~g}^{-1}\right)$ irradiation energy, it has been shown that the amorphous region is first affected 
followed by changes in the crystalline parts (Yang et al., 2017). Our data suggest that for relatively high irradiation energy $\left(400 \mathrm{~W} \mathrm{~g}^{-1}\right)$, the disruption of the amorphous regions could not be monitored and only the effects on the crystalline parts were recorded. Specifically, the microwave treatment resulted in the degradation of starch molecules, thereby inducing rearrangement of crystalline structure while the granule integrity was preserved (Fig. S1). However, due to their molecular and physical differences, AP and AM displayed distinctly different changes in their crystalline structure.

Highly branched AP molecules, also characterized by having a large molecular size, can build an ordered coherent backbone structure thereby contributing to an ordered crystalline structure and regular granular morphology. Therefore, when pure AP molecules are cleaved and disrupted by microwave radiation, crystallinity is decreased. However, when AP molecules are further degraded, the cleaved segments, with much lower molecular size, gain in mobility these can migrate under the high-frequency electric fields and reaggregate resulting in recovered crystallinity.

In contrast, small-size AM molecules are normally present in the normal starch granules. Although pure AM molecules also generated granules in barley, the granules were irregular and highly aggregated and with no lamellar peak (Goldstein et al., 2016), demonstrating a disordered internal structure of AM. Therefore, as AM molecules were degraded by microwave irradiation, the B-type crystalline allomorph was quickly disrupted, demonstrating the instability and strain of AM within these granules. An interesting effect is the formation of $\mathrm{V}_{\mathrm{h}}$-type crystals, which is likely attributed to the high flexibility of AM molecules, especially degraded AM segments, within the granular matrix. Hence, we suggest a new possibility of high gelatinization temperature typical for HAM starch. Due to the high AM content, new and more stable crystals are capable to be formed during heating, thereby increasing the thermal resistance of AM. However, upon further treatment, B-type crystals are completely destroyed and partial $\mathrm{V}_{\mathrm{h}}$ crystals are also disrupted, which is mainly associated with the further cleavage of AM molecules.

Using the same microwave power (400 $\left.\mathrm{W} \mathrm{g}^{-1}\right)$, high AM (50\%) starch underwent similar degradation and aggregation of the AM fraction after a 1-min microwave treatment (Zhong et al., 2019). However, in the HAM starch system, molecular degradation did not further proceed with further microwave treatment, although the crystalline disordering increased (Zhong et al., 2019). This indicates a protecting role of AP in the HAM system which is not present in the pure AM system. A similar effect was found in AP in this study and the previous study (Yang et al., 2017), showing high degradation resistance of starch containing AP. Hence, we suggest, 
under the microwave treatment, the degradation in starch granules is increased with the increase of amylose content in such granules, due to the greater protection effect of amylopectin on granular stability. However, the increase of amylose content also results in the increase the mobility of linear small segments, thereby leading to the re-association of these segments and affecting the crystalline type. However, it worth mentioning that the amylolytic digestibility of starch granules under the microwave treatment is not linearly correlated with the crystallinity. Instead, we suggest that the Mw of degraded starch molecules plays a more important role on the amylolytic resistance of starches. However, the underlying mechanism is not fully explained in this study and need to be further explored in the future.
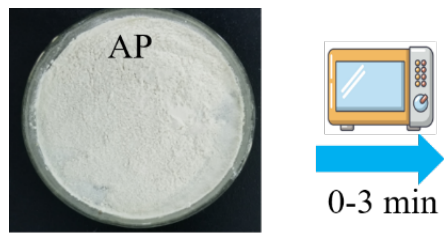

Molecular weight $\downarrow \downarrow$ Crystalline type unchanged Crystallinity $\downarrow$ RS in granular system $\downarrow \downarrow$ RS in retrograded system $\uparrow \uparrow$

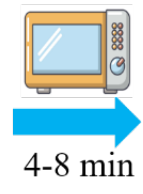

Molecular weight $\downarrow$

Crystalline type unchanged Crystallinity $\uparrow \uparrow$ RS in granular system $\uparrow$ RS in retrograded system $\downarrow \downarrow$

Molecular weight $\downarrow \downarrow$
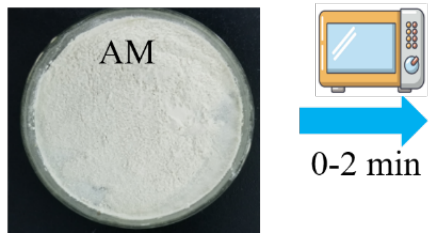
B-type crystal $\downarrow$ Vh-type crystal $\uparrow$ Crystallinity $\uparrow$ 0-2 min RS in granular system $\downarrow \downarrow$

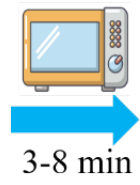

Molecular weight $\downarrow$

B-type crystal $\downarrow$

Vh-type crystal $\downarrow$

Crystallinity $\downarrow \downarrow$
RS in granular system $\uparrow \uparrow \uparrow$

Figure 6. How the structure and digestibility of AM and AP granular starches changed by microwave heating.

\subsection{The effects of microwave treatment on the functionality of pure AP and AM systems}

Our data demonstrate that a microwave treatment can increase the water solubility and decrease the swelling power of both AP and AM separately. The effect on the water solubility was the most dominant. For AP, treatment weakened the strength of AP gels (3-4 min treatment), but increased the plastic behavior and deformability (6-8 min treatment). In contrast, short-time microwave treatment of AM increased the gel strength, whereas its effect on the elastic and plastic behavior of the gel was limited. Initially, the amylolytic susceptibility was increased for both AP and AM and then it decreased as an effect of re-association of the glucan fragments produced during treatment. As expected, re-associated AM molecules were more resistant to amylase hydrolysis than re-associated AP molecules, as demonstrated by the increase in RS in the AM system and the increase of SDS in the AP system. The effect on amylolytic resistance was highly related to the treatment time. The enzymatic resistance of AP 
increased within the first 3 min to reach a maximum, while the enzymatic resistance of AM started increasing from the fourth minute whereafter the resistance kept increasing with treatment time.

\section{Conclusion}

The effects of relatively high energy microwave treatment on the structure and functional properties of native granular pure AM and AP systems were compared. The treatments resulted in the degradation of AM and AP molecules in both samples. The crystallographic data confirmed the high level of AM degradation and aggregation and the formation of $\mathrm{V}_{\mathrm{h}}$-type crystalline allomorph in the AM granular system during the first 2 min of microwave treatment, as demonstrated by the increase in crystallinity. However, the RS content decreased during the period, implying that AM re-aggregation without involving AP (like for a typical starch granule) was not capable of stabilizing the granular structure. With further treatment, AM degraded the granular AM system but the crystallinity started decreasing, showing that the crystalline regions of AM were mainly damaged by the microwave irradiation. In contrast, the crystallinity in the AP granular system first decreased followed by an increase upon further irradiation, reflecting that in contrast to AM, AP underwent a different structural change. Hence, our study demonstrated specific and dynamic structural changes of AM and AP granular systems under microwave treatment and their different changes in molecular and physical characteristics. Different experimental conditions including microwave power, moisture content and sample weight, will affect the outcome of the product structures. However, we suggest that the structural transformation process of AM and AP granular starches under microwave treatment follows the same process as shown in this study. Hence, the information is helpful for industries to further improve the functionality, like enhancing resistant starch content and improving water solubility and gel strength of AM and AP by controlling the extent of microwave treatment.

\section{Acknowledgment}

Mr. Zhong would like to thank the China Scholarship Council (CSC) (201906300041, 202006150028, 202003250068) funding for his PhD studies at University of Copenhagen (UCPH), Denmark.

\section{Appendix A. Supplementary data}

Supplementary data can be found online at https://doi.org/10.1016/j.foodhyd.2021.106856 


\section{References}

Bertoft, E. (2017). Understanding starch structure: Recent progress. Agronomy, 7(3), 56.

Blennow, A. (2018). Chapter 4 - Starch Bioengineering. In M. Sjöö \& L. Nilsson (Eds.), Starch in Food (Second Edition) (pp. 179-222): Woodhead Publishing.

Blennow, A., Bay-Smidt, A. M., Wischmann, B., Olsen, C. E., \& Møller, B. L. (1998). The degree of starch phosphorylation is related to the chain length distribution of the neutral and the phosphorylated chains of amylopectin. Carbohydrate Research, 307(1), 45-54.

Blennow, A., Jensen, S. L., Shaik, S. S., Skryhan, K., Carciofi, M., Holm, P. B., Hebelstrup, K. H., \& Tanackovic, V. (2013). Future cereal starch bioengineering: cereal ancestors encounter gene technology and designer enzymes. Cereal Chemistry, 90(4), 274-287.

Braşoveanu, M., \& Nemţanu, M. R. (2014). Behaviour of starch exposed to microwave radiation treatment. Starch, 66(1-2), 3-14.

Brückner, S. (2000). PULWIN: A program for analyzing powder X-ray diffraction patterns. Journal of Applied Crystallography, 33, 977-979.

Carciofi, M., Blennow, A., Jensen, S. L., Shaik, S. S., Henriksen, A., Buléon, A., Holm, P. B., \& Hebelstrup, K. H. (2012). Concerted suppression of all starch branching enzyme genes in barley produces amylose-only starch granules. BMC Plant Biology, 12(1), 223-223.

Chandrasekaran, S., Ramanathan, S., \& Basak, T. (2013). Microwave food processing-A review. Food Research International, 52(1), 243-261.

Cheetham, N. W. H., \& Tao, L. (1998). Variation in crystalline type with amylose content in maize starch granules: an X-ray powder diffraction study. Carbohydrate Polymers, 36(4), 277-284.

Doner, L. W., \& Irwin, P. L. (1992). Assay of reducing end-groups in oligosaccharide homologues with 2, 2'-bicinchoninate. Analytical Biochemistry, 202(1), 50-53.

Emami, S., Perera, A., Meda, V., \& Tyler, R. T. (2012). Effect of microwave treatment on starch digestibility and physico-chemical properties of three barley types. Food and Bioprocess Technology, 5(6), 2266-2274.

Fan, D., Ma, W., Wang, L., Huang, J., Zhang, F., Zhao, J., Zhang, H., \& Chen, W. (2013). Determining the effects of microwave heating on the ordered structures of rice starch by NMR. Carbohydrate Polymers, 92(2), 1395-1401.

Franck, A. (2004). Understanding rheology of structured fluids. Book of TA instruments, 1-17.

Galema, S. A. (1997). Microwave Chemistry. Chemical Society Reviews, 26(3), 233-238.

Goldstein, A., Annor, G., Putaux, J.-L., Hebelstrup, K. H., Blennow, A., \& Bertoft, E. (2016). Impact of full range of amylose contents on the architecture of starch granules. International Journal of Biological Macromolecules, 89, 305-318.

Green, M. M., Blankenhorn, G., \& Hart, H. (1975). Which starch fraction is water-soluble, amylose or amylopectin? Journal of Chemical Education, 52(11), 729.

Guan, S., Wang, P., Liu, H., Liu, G., Ma, Y., \& Zhao, L. (2011). Production of high-amylose maize lines using RNA interference in sbe2a. African Journal of Biotechnology, 10(68), $15229-15237$.

Hebelstrup, K. H., Sagnelli, D., \& Blennow, A. (2015). The future of starch bioengineering: GM microorganisms or GM plants? Frontiers in Plant Science, 6, 247.

Jackson, D., Waniska, R., \& Rooney, L. W. (1989). Differential water solubility of corn and sorghum starches as characterized by high-performance size-exclusion chromatography. Cereal Chemistry, 66(3), 228-232. 
Keeratiburana, T., Hansen, A. R., Soontaranon, S., Blennow, A., \& Tongta, S. (2020). Porous high amylose rice starch modified by amyloglucosidase and maltogenic $\alpha$-amylase. Carbohydrate Polymers, 230, 115611.

Lewandowicz, G., Fornal, J., \& Walkowski, A. (1997). Effect of microwave radiation on physico-chemical properties and structure of potato and tapioca starches. Carbohydrate Polymers, 34(4), 213-220.

Lewandowicz, G., Jankowski, T., \& Fornal, J. (2000). Effect of microwave radiation on physico-chemical properties and structure of cereal starches. Carbohydrate Polymers, 42(2), 193-199.

Lii, C. Y., \& Chang, Y. H. (1991). Study of starch in Taiwan. Food Reviews International, 7(2), 185-203.

Luo, Z., He, X., Fu, X., Luo, F., \& Gao, Q. (2006). Effect of microwave radiation on the physicochemical properties of normal maize, waxy maize and amylomaize V starches. Starch-Stärke, 58(9), 468-474.

Maniglia, B. C., Castanha, N., Le-Bail, P., Le-Bail, A., \& Augusto, P. E. (2020). Starch modification through environmentally friendly alternatives: a review. Critical Reviews in Food Science and Nutrition, 1-24. DOI: 10.1080/10408398.2020.1778633

Mutlu, S., Kahraman, K., \& Öztürk, S. (2017). Optimization of resistant starch formation from high amylose corn starch by microwave irradiation treatments and characterization of starch preparations. International Journal of Biological Macromolecules, 95, 635-642.

Nishiyama, Y., Mazeau, K., Morin, M., Cardoso, M. B., Chanzy, H., \& Putaux, J.-L. (2010). Molecular and crystal structure of 7-fold V-amylose complexed with 2propanol. Macromolecules, 43(20), 8628-8636.

Oyeyinka, S. A., Umaru, E., Olatunde, S. J., \& Joseph, J. K. (2019). Effect of short microwave heating time on physicochemical and functional properties of Bambara groundnut starch. Food Bioscience, 28, 36-41.

Shaik, S.S., Carciofi, M., Martens, H.J., Hebelstrup, K.H., and Blennow, A. (2014) Starch bioengineering affects cereal grain germination and seedling establishment. Journal of Experimental Botany, 65/9, 2257-2270.

Shaik, SS, Obata, T, Hebelstrup, KH, Fernie, AR, Mateiu, RV, Blennow, A. (2016) Starch granule re-structuring by starch branching enzyme and glucan water dikinase modulation affects caryopsis physiology and metabolism. PLOS ONE, 11(2), e0149613.

Sun, M., Sun, H., Wang, Y., Sánchez-Soto, M., \& Schiraldi, D. A. (2018). The relation between the rheological properties of gels and the mechanical properties of their corresponding aerogels. Gels, 4(2), 33.

Tester, R. F., \& Morrison, W. R. (1990). Swelling and gelatinization of cereal starches. I. Effects of amylopectin, amylose, and lipids. Cereal Chemistry, 67(6), 551-557.

Vanier, N. L., El Halal, S. L. M., Dias, A. R. G., \& da Rosa Zavareze, E. (2017). Molecular structure, functionality and applications of oxidized starches: A review. Food Chemistry, $221,1546-1559$.

Vamadevan, V., \& Bertoft, E. (2018). Impact of different structural types of amylopectin on retrogradation. Food Hydrocolloids, 80, 88-96.

Wang, S., \& Copeland, L. (2012). Phase transitions of pea starch over a wide range of water content. Journal of Agricultural and Food Chemistry, 60(25), 6439-6446.

Yang, Q., Qi, L., Luo, Z., Kong, X., Xiao, Z., Wang, P., \& Peng, X. (2017). Effect of microwave irradiation on internal molecular structure and physical properties of waxy maize starch. Food Hydrocolloids, 69, 473-482. 
Zeng, S., Chen, B., Zeng, H., Guo, Z., Lu, X., Zhang, Y., \& Zheng, B. (2016). Effect of microwave irradiation on the physicochemical and digestive properties of lotus seed starch. Journal of Agricultural and Food Chemistry, 64(12), 2442-2449.

Zhang, J., Chen, F., Liu, F., \& Wang, Z. W. (2010). Study on structural changes of microwave heat-moisture treated resistant Canna edulis Ker starch during digestion in vitro. Food Hydrocolloids, 24(1), 27-34.

Zhong, Y., Keeratiburana, T., Kirkensgaard, J. J. K., Khakimov, B., Blennow, A., \& Hansen, A. R. (2021). Generation of short-chained granular corn starch by maltogenic $\alpha$-amylase and transglucosidase treatment. Carbohydrate Polymers, 251, 117056.

Zhong, Y., Liang, W., Pu, H., Blennow, A., Liu, X., \& Guo, D. (2019). Short-time microwave treatment affects the multi-scale structure and digestive properties of high-amylose maize starch. International Journal of Biological Macromolecules, 137, 870-877.

Zhong, Y., Liu, L., Qu, J., Blennow, A., Hansen, A. R., Wu, Y., Guo, D., \& Liu, X. (2020). Amylose content and specific fine structures affect lamellar structure and digestibility of maize starches. Food Hydrocolloids, 105994.

Zhong, Y., Liu, L., Qu, J., Li, S., Blennow, A., Seytahmetovna, S. A., et al. (2020). The relationship between the expression pattern of starch biosynthesis enzymes and molecular structure of high amylose maize starch. Carbohydrate Polymers, 247, 116681. 